\title{
Evaluating Drought Monitoring Methods Using Remote Sensing: A Dynamic Correlation Analysis Between Heat Fluxes and Land Cover Patterns
}

\author{
Zhiqiang Gao, Ning Xu, Chuancheng Fu, and Jicai Ning
}

\begin{abstract}
We obtained data from remotely sensed images using a two-phase preprocessing and retrieving approach. The spatial relationships between the Normalized Difference Vegetation Index (NDVI) and heat fluxes were studied, and the capability of monitoring indices [i.e., Normalized Difference Water Index (NDWI), Temperature Vegetation Dryness Index (TVDI), and Soil Moisture Monitoring Index (SMMI)] to depict regional soil moisture and monitor regional drought was analyzed. The following conclusions were obtained. The relationships between the NDVI and heat fluxes are significantly affected by land cover; specifically, these relationships depend on the density of vegetative cover. When monitoring regional soil moisture and drought, the appropriate index (TVDI, NDWI, or SMMI) should be selected based on drought severity and other associated characteristics.
\end{abstract}

Index Terms-Correlation, drought monitoring, heat flux, land cover, soil moisture.

\section{INTRODUCTION}

$\mathbf{M}$ ONITORING large-scale heat fluxes and soil moisture via remote sensing technology is important for the accurate evaluation of water resources, climate, ecology, and agriculture. The hydrothermal processes of water, heat, and momentum exchange intimately correlate the atmosphere with soil and vegetation conditions. Therefore, these processes are of interest to many disciplines, such as meteorology, hydrology, ecology, and agriculture.

Goward and Hope [1] and Price [2] developed the vegetation index/temperature trapezoid (VITT) eigenspace of land surface temperature (LST)-Normalized Difference Vegetation Index (NDVI), and Ridd [3] and Gilles and Carlson [4], [5] analyzed surface evapotranspiration and soil moisture. Mcffters et al. [6] first proposed the Normalized Difference Water Index (NDWI) by combining the TM green band and TM near-infrared band.

Manuscript received November 06, 2013; revised July 20, 2014; accepted September 12, 2014. Date of publication October 07, 2014; date of current version February 04, 2015. This work was supported in part by the Key Research Program of the Chinese Academy of Sciences under Grant KZZDEW-14, in part by the National Science and Technology Support Program under Grant 2014FY210600, in part by the National Natural Science Foundation of China under Grant 41171334, in part by the Talent Fund of Yantai Institute of Coastal Zone Research, in part by the Ecological Innovation and Breeding Project under Grant Y254021031 and Grant Y355031061, and in part by the USDA NIFA Project under Grant 2010-34263-21075. (Corresponding author: Zhiqiang Gao.)

The authors are with the Yantai Institute of Coastal Zone Research, Chinese Academy of Sciences, Yantai 264003, China (e-mail: zqgao@yic.ac.cn).

Color versions of one or more of the figures in this paper are available online at http://ieeexplore.ieee.org.

Digital Object Identifier 10.1109/JSTARS.2014.2359657
Based on VITT, Sandholt et al. [7] proposed the Temperature Vegetation Dryness Index (TVDI) to monitor regional drought. Wang and Qu [8] developed the Normalized Multiband Drought Index (NMDI) to monitor soil and vegetation moisture from space.

This paper analyzes the spatial relationship between the NDVI and heat flux and evaluates the ability of three indices [NDWI, TVDI, and Soil Moisture Monitoring Index (SMMI)] to monitor soil moisture and detect drought. These indices provide scientific guidance for monitoring regional soil moisture and drought based on data that is extracted from two-phase, remotely sensed images.

\section{Study Methods}

\section{A. Study Area}

The study area is located at Laizhou Bay in Shandong Province, China $\left(36^{\circ} 48^{\prime} 43^{\prime \prime} \mathrm{N}\right.$ to $37^{\circ} 32^{\prime} 49^{\prime \prime} \mathrm{N}$ and $118^{\circ} 37^{\prime} 37^{\prime \prime} \mathrm{E}$ to $119^{\circ} 44^{\prime} 31^{\prime \prime} \mathrm{E}$ ) (Fig. 1). The lengths of the study area in the east-west and north-south directions are approximately $97 \mathrm{~km}$ and $79 \mathrm{~km}$, respectively. The total study area is 486245 hectares. The sediment that is distributed in the alluvial plain ranges from fine sand (close to the low water line) to mud that is transported by flood currents. Because the area is located near the open ocean, it is characterized by a moist, warm, and temperate continental monsoon climate [9].

\section{B. Retrieving Land Surface Heat Fluxes and Vegetation Index}

To estimate the heat fluxes $\left(R_{n}, G_{n}, H\right.$, and $\left.L E\right)$ in this study, Landsat satellite images were analyzed using a surface energy balance with a topography algorithm (SEBTA) [10].

Based on the heat flux settings and SEBTA processes, a computer program can be designed using Arc/Info 9.0 Macro Language (AML) and Compaq Visual FORTRAN 6.5 mixedlanguage programming to generate the ultimate SEBTA computational code. The SEBTA computer package can be operated in a Microsoft Windows System using the ESRI GRID module as the major data format. Figs. 2 and 3 present the land surface heat fluxes of 1987.

The calculating NDVI, NDWI, and SMMI are derived from the algorithms of NDVI [11], NDWI [6], and SMMI [12]. Figs. 3(b) and 4 present the spatial distribution of NDVI, NDWI, and SMMI. 


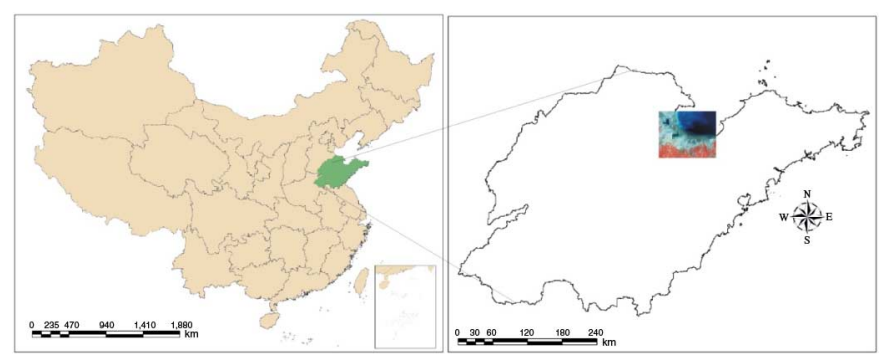

Fig. 1. Study area in Shandong Province, China.

\section{Calculating the RWSI and TVDI}

Referencing the definition of the Crop Water Stress Index (CWSI) [13], this article defines the Regional Water Stress Index (RWSI) as follows:

$$
R W S I=1-\frac{\lambda E T}{\lambda E T_{w e t}}=\frac{H}{R_{n}-G}
$$

where $H$ is the sensible heat flux, $R_{n}$ is the net radiation flux, and $G$ is the soil heat flux. These parameters are calculated using the SEBTA model. Therefore, the regional deficit of water (drought) can be monitored over time using remote sensing technology.

The combination of the vegetation index and the LST provides the VITT eigenspace. Because soil moisture contour lines occur within the VITT, Sandholt et al. [7] studied the simplified triangle space of the LST-NDVI and proposed the TVDI to detect soil moisture. The TVDI is defined as

$$
\mathrm{TVDI}=\frac{T s-T s_{\min }}{T s_{\max }-T s_{\min }}
$$

where $T s_{\min }$ is the minimum temperature of the wet land surface that corresponds to the NDVI, $T s_{\max }$ is the maximum temperature of the dry land surface that corresponds to the NDVI, and Ts is the LST corresponding to any pixel. Fig. 5 presents the spatial distribution of RWSI and TVDI in 2000.

\section{RESULTS}

\section{A. Relational Analysis of Surface Heat Fluxes With NDVIs}

Scholars have extensively studied the relationships between LST and vegetation indices [1], [2], [7], [14]. In this paper, the regional sensible heat flux $(H H)$, latent heat flux $(L E)$, and soil heat flux $\left(G_{n}\right)$ were retrieved using the SEBTA model [10], and the relationships between surface heat fluxes and NDVIs were analyzed.

By combining the NDVI data from various periods (1987 and 2000) with the corresponding surface heat flux data, we queried the pixels for index values at 0.01 intervals and averaged the surface heat fluxes for the corresponding NDVI pixels to generate a NDVI dataset and obtain new surface heat fluxes. Then a scatter diagram between the NDVI and surface heat flux was created.

Fig. 6(a) presents the scatter diagram of NDVIs and sensible heat fluxes. This scatter diagram indicates that the type of land cover greatly affects the relationship between the NDVI and sensible heat flux. Different relationships between the NDVI and sensible heat flux exist for varying degrees of vegetative coverage. As the NDVI increases, the sensible heat flux gradually increases. The sensible heat flux gradually decreases as the NDVI increases. Two critical points (where NDVI $=0.11$ and 0.59) are apparent in the NDVI-heat flux scatter diagram for 2000. When the NDVI is greater than 0.59, the correlation between the NDVI and sensible heat flux is positive and the heat flux increases with increasing NDVIs. However, this correlation is negative in 1987. Therefore, the heat island effect resulted in a weak positive correlation between the sensible heat flux and NDVI in 2000.

Fig. 6(b) presents the scatter diagram of latent heat fluxes and NDVIs for the two separate years. The diagram indicates that different relationships exist between the latent heat flux and NDVI for various densities of vegetation. The latent heat flux is predominantly affected by bare land, which results in a negative correlation between the latent heat flux and the NDVI. In these areas, the land is mainly characterized by high-density vegetation, such as farmland, grassland, and forests, where significant transpiration occurs. The latent heat flux increases with increasing vegetation density and NDVI values.

Fig. 6(c) presents the scatter diagram for NDVIs and soil heat fluxes (1987 and 2000). Different relationships exist between the NDVI and soil heat flux for varying densities of vegetation. The soil heat flux gradually decreases as the NDVI increases. Areas with NDVIs within these ranges are characterized by bare beach and saline-alkali land, where there is a low density of vegetation, and a negative correlation between the $G_{n}$ and NDVI.

\section{B. Drought Monitoring and Response Analysis of LULC}

In this research, the RWSI was calculated after the regional heat fluxes were obtained using the SEBTA model. Using RWSI as the standard for regional water shortage, we analyzed the spatial characteristics of various indices (TVDI, NDWI, and SMMI) and their ability to indicate soil moisture and monitor drought conditions.

We superimposed the RWSI (1987 and 2000) with the corresponding TVDI, NDWI, and SMMI. Then, we queried pixels for index values at an interval of 0.01 and calculated the values corresponding to the TVDI, NDWI, and SMMI. RWSI datasets were generated for each index to create a scatter diagram (Fig. 7). We analyzed the correlations between the RWSI and the three drought monitoring indices, and then we assessed the surface moisture conditions and the ability of each index to monitor drought.

Fig. 7(a) displays a scatter diagram of the TVDI versus the RWSI. Referring to Table I, we observed that the TVDI correctly depicts the state of soil water during mild drought, normal, and moist conditions; however, the index does not accurately convey the soil water status for moderate or severe droughts. Therefore, we suggest that the TVDI is not a useful index to monitor the shortage of soil water during moderate and severe droughts. 


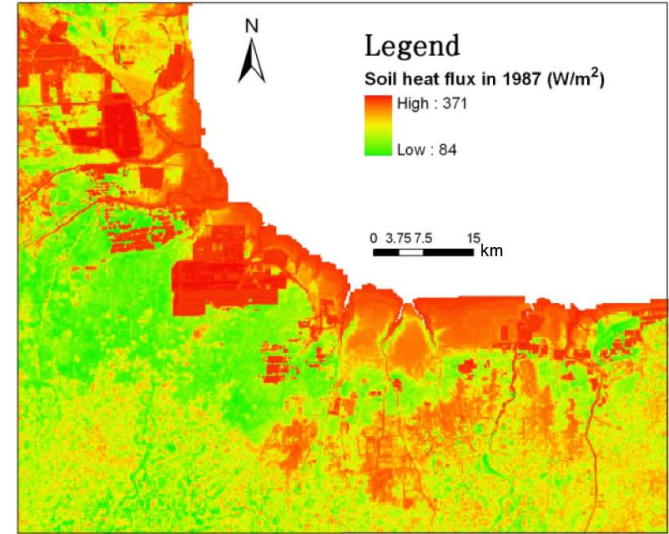

(a)

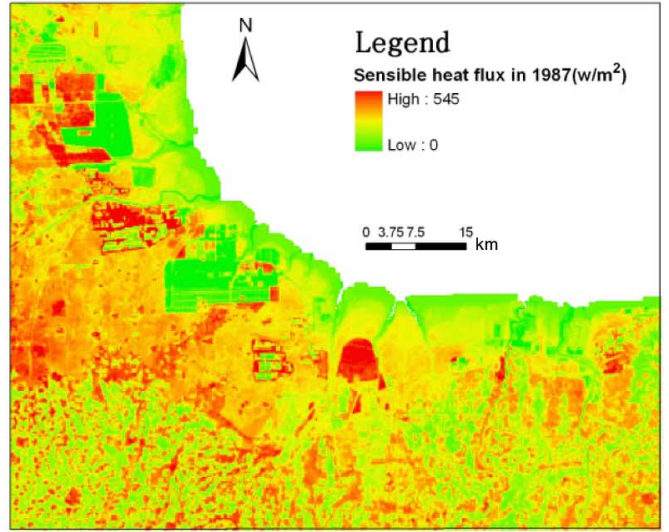

(b)

Fig. 2. Spatial distribution maps of the (a) soil heat flux and (b) sensible heat flux in 1987.

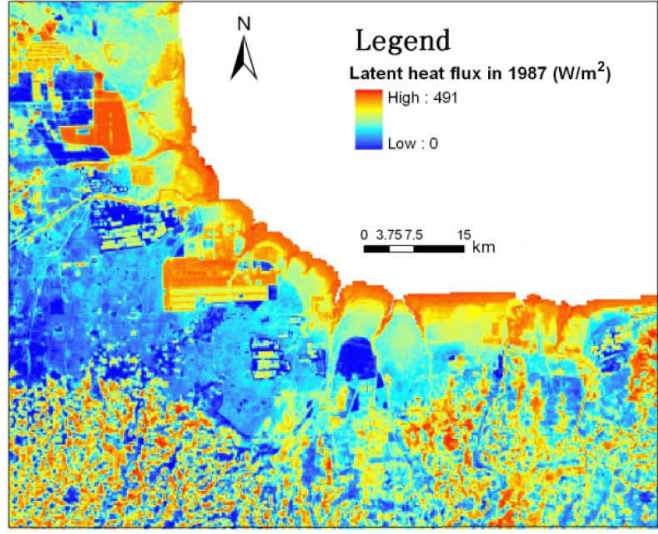

(a)

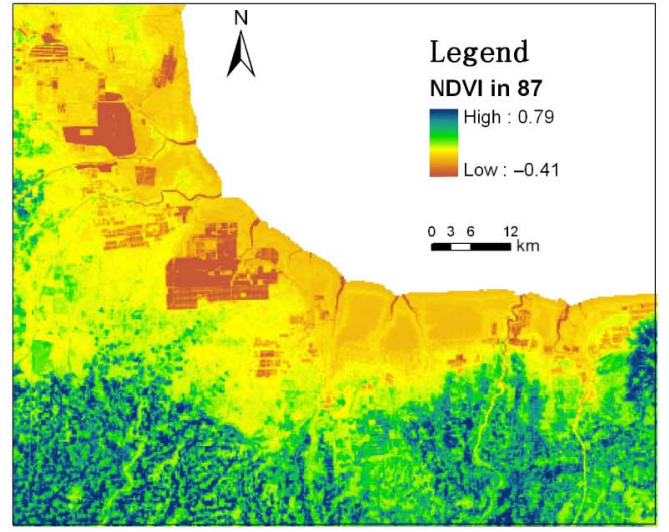

(b)

Fig. 3. Spatial distribution maps of the (a) latent heat flux and (b) NDVI in 1987.

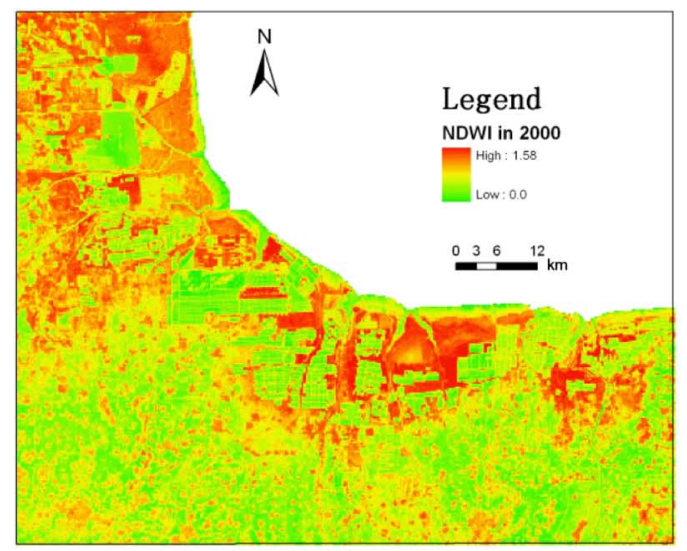

(a)

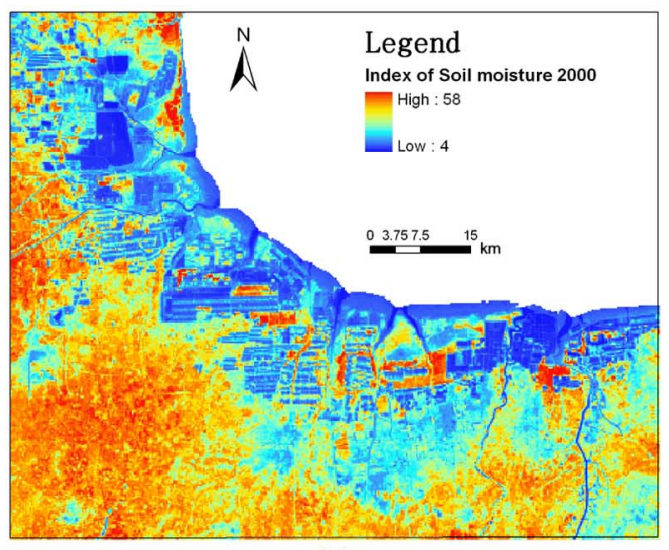

(b)

Fig. 4. Spatial distribution maps of the (a) NDWI and (b) SMMI in 2000.

Fig. 7(b) depicts the spatial relationship (scatter diagram) between SMMI and RWSI. We found that the SMMI has some ability to depict soil water status and the degree of drought. When the RWSI is less than 0.7 in a region without vegetative cover, the SMMI can accurately depict soil water status and the degree of drought. However, it cannot be used to monitor regional drought and soil moisture in areas with vegetation. 


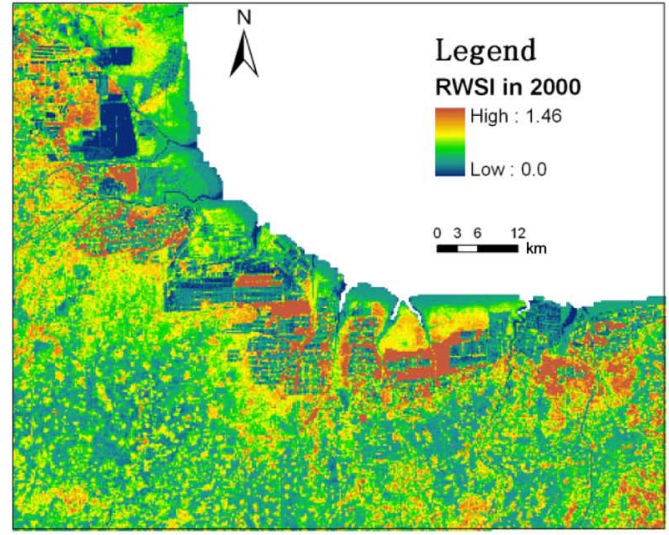

(a)

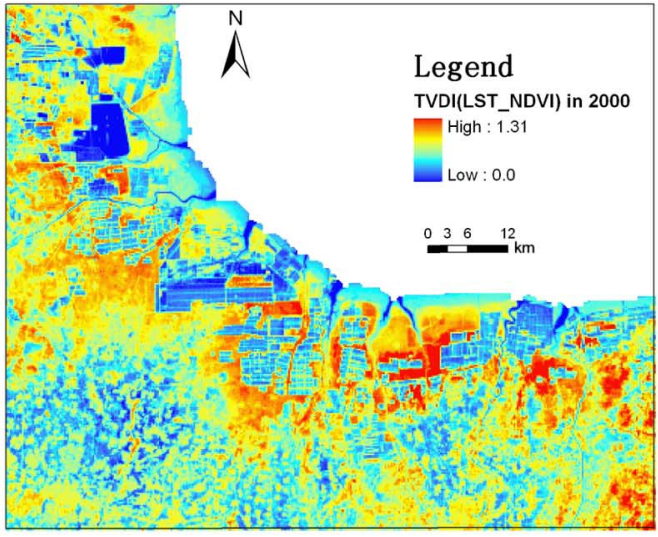

(b)

Fig. 5. Spatial distribution maps of the (a) RWSI and (b) TVDI in 2000.

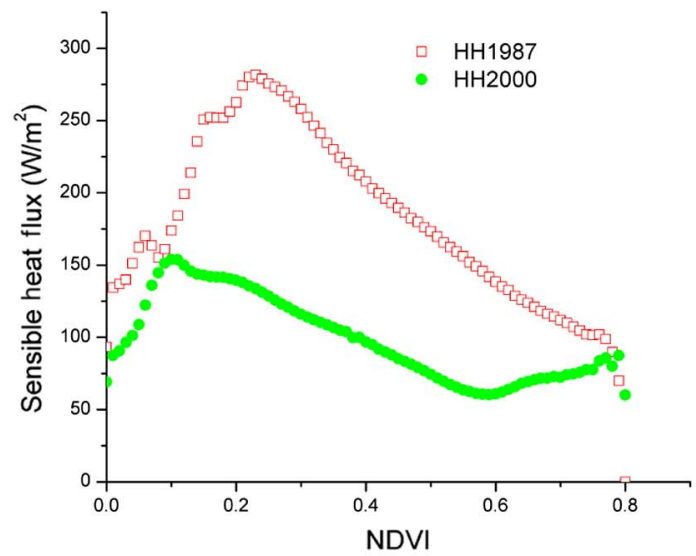

(a)

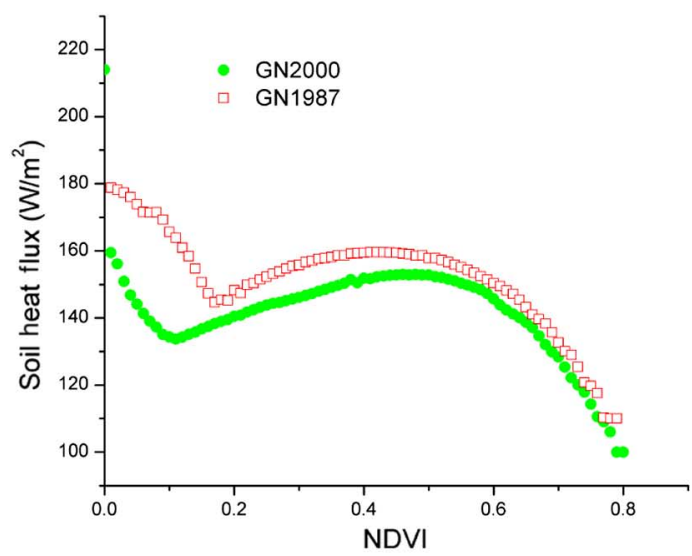

(c)

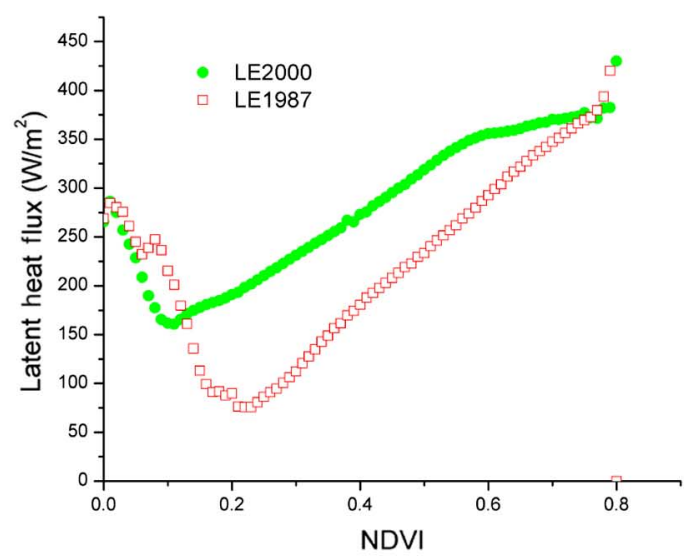

(b)

Fig. 6. Scatter diagram of the NDVI and heat flux for various periods. (a) Sensible heat flux. (b) Latent heat flux. (C) Soil heat flux.

The scatter diagram of the relationship between the NDWI and the RWSI is presented in Fig. 7(c). Although the NDWI has some degree of certainty in expressing soil moisture and drought conditions, it cannot correctly depict the state of soil water. Furthermore, the correlation between the NDWI and RWSI is weak when the land surface is covered with water features. Referring to Table I, the NDWI predominately depicts normality, slight drought, moderate drought, and severe droughts. Therefore, the NDWI can be used to monitor regional drought; however, wet conditions cannot be accurately depicted by the NDWI. 


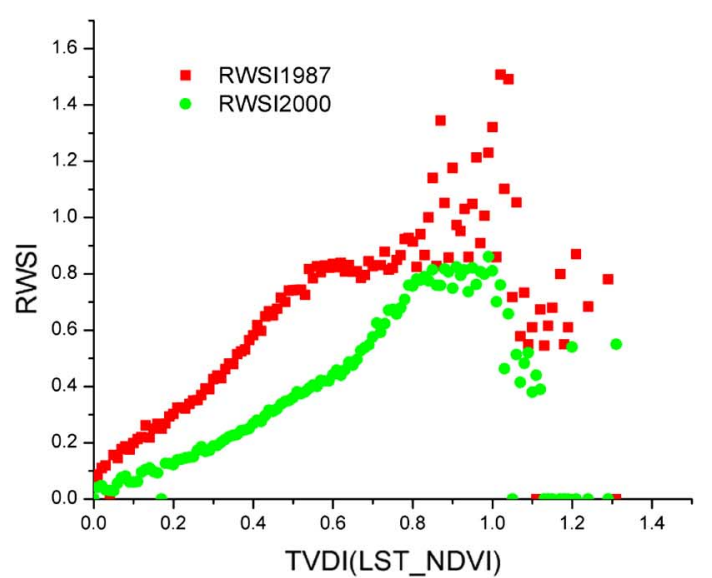

(a)

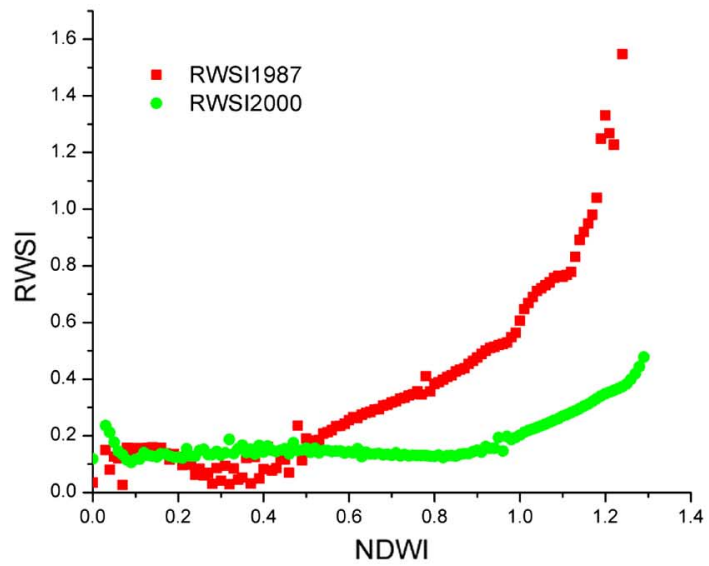

(c)

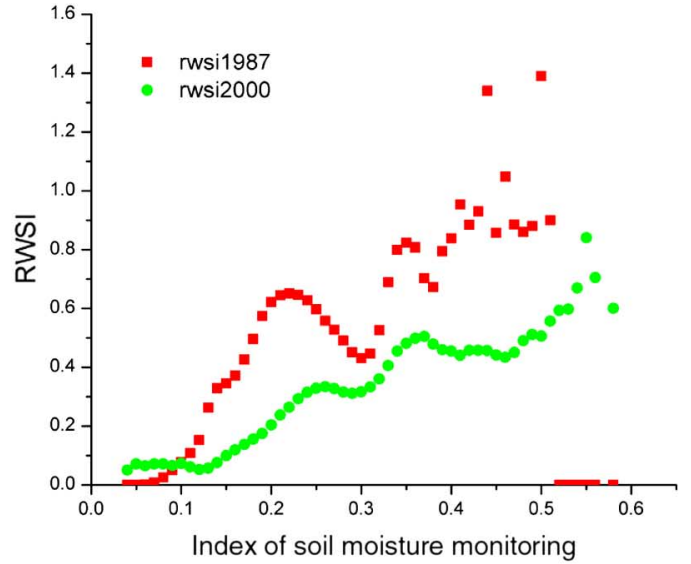

(b)
Fig. 7. Scatter plots of the RWSI and droug
TABLE

REgIONAL Drought ClassificATION STANDARDS

\begin{tabular}{cccc}
\hline Class & Relative moisture & RWSI & Level \\
\hline 1 & $<0.4$ & $>0.892$ & Severe drought \\
2 & $0.4-0.5$ & $0.752-0.892$ & Moderate drought \\
3 & $0.5-0.6$ & $0.612-0.752$ & Slight drought \\
4 & $0.6-0.8$ & $0.332-0.612$ & Normality \\
5 & $>0.8$ & $<0.332$ & Wetness \\
\hline
\end{tabular}

\section{CONCLUSION}

In this paper, land cover classification information was extracted from two-phase remotely sensed images using computer-aided preprocessing. The regional surface heat fluxes (i.e., sensible, latent, and soil heat flux) were derived using the SEBTA model, and the RWSI was calculated from the RWSI. Using the VITT eigenspace proposed by Sandholt et al. [7], the TVDI was calculated and the corresponding NDWI and SMMI values were obtained. Based on LULC data and related indices, the spatial relationships between the NDVI and heat fluxes were obtained. The RWSI was set as the reference standard for regional soil moisture deficiency. We analyzed the correlations among the TVDI, NDWI, and SMMI (after combining with the RWSI) and determined the ability of each to detect soil moisture and monitor drought conditions. The following are the main conclusions.

1) Land cover significantly affects heat fluxes. Different relationships exist between the NDVI and heat fluxes depending on the density of vegetative cover. For areas with a low density of vegetation, a positive correlation exists between the sensible heat flux and the NDVI and a negative correlation exists between the latent heat flux (or soil heat flux) and the NDVI. A negative correlation exists between the sensible heat flux and the NDVI and a positive correlation exists between the latent heat flux (or soil heat flux) and the NDVI for areas with high density of vegetation.

2) Assuming that the RWSI is the standard for regional soil water deficiency, we analyzed the characteristics and applicability of regional water monitoring using the TVDI, NDWI, and SMMI. We observed that the TVDI can depict mild drought, normal, and moist conditions correctly, but it cannot accurately indicate the water deficiency of moderate or severe droughts. In addition to soil water conditions, the NDWI can describe normal, slight, moderate, and severe droughts, but it cannot accurately depict wet conditions. However, a strong relationship does not exist between the NDWI and the RWSI for 
extremely moist surface conditions. Therefore, the SMMI has some degree of certainty in depicting soil water conditions and the degree of drought. Although the RWSI can accurately depict the regional soil water conditions when it is less than 0.7 , the index cannot be used to monitor regional drought or soil moisture in areas with high density of vegetation.

3) The magnitude of water shortage monitored by the RWSI was higher in 1987 than 2000, and the TVDI, NDWI, or SMMI were all unable to accurately detect the difference in water deficit between 1987 and 2000 because of the effect of background soil conditions (i.e., soil temperature and soil brightness).

In summary, land cover characteristics significantly affect the relationships between the NDVI and heat fluxes. Additionally, the regional sensible, latent, and soil heat fluxes depend on the density of vegetative cover. Because the three specified indices (TVDI, NDWI, and SMMI) have limitations in monitoring soil moisture and drought conditions, each index should be carefully considered based on its abilities and the severity of the regional drought.

In future studies, we will validate the results and conclusions in this paper with recently obtained ETM and Chinese CBERS data in the Yellow River delta and the North China Plain to further confirm the conclusions described above.

\section{ACKNOWLEDGMENT}

The authors would like to thank the anonymous reviews for their insightful comments and help to the manuscript.

\section{REFERENCES}

[1] S. N. Goward and A. S. Hope, "Evaporation from combined reflected solar and emitted terrestrial radiation: Preliminary FIFE results from AVHRR data," Adv. Space Res., vol. 9, no. 4, pp. 239-249, 1989.

[2] J. C. Price, "Using spatial context in satellite data to infer regional scale evapotranspiration," IEEE Trans. Geosci. Remote Sens., vol. 28, no. 5, pp. 940-948, Sep. 1990.

[3] M. K. Ridd, "Exploring a V-I-S (vegetation-impervious surface-soil) model for urban ecosystem analysis through remote sensing: Comparative anatomy for citied," Int. J. Remote Sens., vol. 16, no. 3, pp. 2165-2185, 1995.

[4] R. R. Gilles and T. N. Carlson, "Thermal remote sensing of surface soil water content with partial vegetation cover for incorporation into climate models," J. Appl. Meteorol., vol. 34, no. 3, pp. 745-756, 1995.

[5] R. R. Gilles and T. N. Carlson, "A verification of the "triangle method for obtaining surface soil water content and energy fluxes from remote measurements of the Normalized Difference Vegetation Index (NDVI) and surface radiant temperature," Int. J. Remote Sens., vol. 18, no. 5, pp. 3145-3166, 1997.

[6] S. K. Mcffters, "The use of the Normalized Difference Water Index (NDWI) in the delineation of open water features," Int. J. Remote Sens., vol. 17, no. 7, pp. 1425-1432, 1996.

[7] I. Sandholt, K. Rasmussen, and J. Andersen, "A simple interpretation of the surface temperature/vegetation index space for assessment of surface moisture status," Remote Sens. Environ., vol. 79, no. 4, pp. 213-224, 2002.

[8] L. L. Wang and J. J. Qu, "NMDI: A Normalized Multi-Band Drought Index for monitoring soil and vegetation moisture with satellite remote sensing," Geophys. Res. Lett., vol. 34, no. 20, p. L20405, 2007.
[9] Q. Wang, Z. Ren, and G. Sun, "Research on seawater intrusion disaster in south- east coastwise area of Laizhou Bay," Mar. Environ. Sci., vol. 21, no. 4, pp. 10-13, 2002.

[10] Z. Q. Gao, C. S. Liu, W. Gao, and N. B. Chang, "A coupled remote sensing and the surface energy balance with topography algorithm (SEBTA) to estimate actual evapotranspiration under complex terrain," Hydrol. Earth Syst. Sci., vol. 15, no. 5, pp. 119-139, 2011.

[11] C. J. Tucker, "Red and photographic infrared linear combinations for monitoring vegetation," Remote Sens. Environ., vol. 8, no. 2, pp. 127-150, 1979.

[12] Z. M. Zhan, Q. M. Qin, A. Ghulan, and D. D. Wang, "NIR-red spectral space based new method for soil moisture monitoring," Sci. China Ser. D-Earth Sci., vol. 50, no. 2, pp. 283-289, 2007.

[13] R. D. Jackson and S. B. Idso, "Canopy temperature as a crop water stress indicator," Water Resour. Res., vol. 17, no. 5, pp. 133-138, 1981.

[14] T. N. Carlson, W. J. Capehart, and R. R. Gillies, "A new look at the simplified method for remote sensing of daily evapotranspiration," Remote Sens. Environ., vol. 54, no. 3, pp. 161-167, 1995.

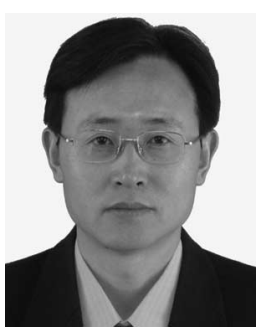

Zhiqiang Gao received the Master's degree from the Institute of Xinjiang Geography, Chinese Academy of Science, Urumqi, China, in 1993, and the $\mathrm{Ph} . \mathrm{D}$. degree from the Institute of Remote Sensing Application, Chinese Academy of Science, in 1998, both in mapping and geographic information system.

$\mathrm{He}$ is a Professor with the University of Chinese Academy of Science, Beijing, China and a Research Scientist with the Yantai Institute of Coastal Zone Research, Chinese Academy of Science. His research interests include remote sensing application and model simulation in coastal zone.

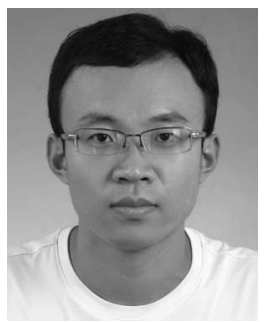

Ning Xu received the Master's degree in ecology, in 2013, and is currently pursuing the Ph.D. degree from the University of Chinese Academy of Science, Yantai, China, both in land cover mapping and geographic information system.

$\mathrm{He}$ is a Research Assistant with the Yantai Institute of Coastal Zone Research, Chinese Academy of Sciences, Beijing, China. His research interests include land use/cover change and environment remote sensing.

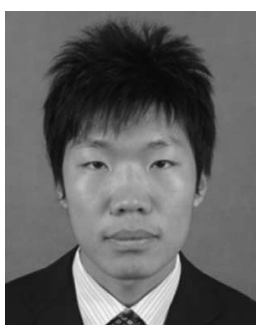

Chuancheng Fu received the Master's degree in soil science from the Nanjing Agricultural University, Nanjing, China, in 2014, and is currently pursuing the $\mathrm{Ph} . \mathrm{D}$. degree at the University of Chinese Academy of Science, Yantai, China, both in soil mapping and geographic information system.

$\mathrm{He}$ is a Research Assistant with the Yantai Institute of Coastal Zone Research, Chinese Academy of Sciences, Beijing, China. His research interests include intertidal zone detection and monitoring based on $3 \mathrm{~S}$ technology.

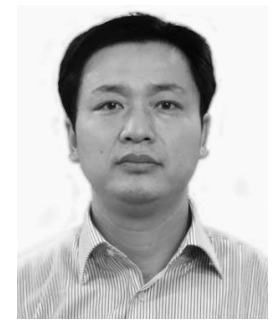

Jicai Ning received the Ph.D. degree in cartography and geography information system from the Institute of Geographic Science and Natural Resources Research, Chinese Academy of Sciences (CAS), Beijing, China, in 2011.

$\mathrm{He}$ was an Assistant Professor with the Yantai Institute of Coastal Zone Research, CAS. His research interests include environment remote sensing and hydrology model. 